Article

\title{
Crop Condition Assessment with Adjusted NDVI Using the Uncropped Arable Land Ratio
}

\section{Miao Zhang, Bingfang Wu *, Mingzhao Yu, Wentao Zou and Yang Zheng}

Key Laboratory of Digital Earth Science, Institute of Remote Sensing and Digital Earth, Chinese Academy of Sciences, Olympic Village Science Park, W. Beichen Road, Beijing 100101, China; E-Mails: zhangmiao@radi.ac.cn (M.Z.); yumz@radi.ac.cn (M.Y.); zouwt@radi.ac.cn (W.Z.); zhengyang@radi.ac.cn (Y.Z.)

* Author to whom correspondence should be addressed; E-Mail: wubf@radi.ac.cn; Tel.: +86-10-6485-5689; Fax: +86-10-6485-8721.

Received: 19 January 2014; in revised form: 31 May 2014 / Accepted: 3 June 2014 / Published: 19 June 2014

Abstract: Crop condition assessment in the early growing stage is essential for crop monitoring and crop yield prediction. A normalized difference vegetation index (NDVI)-based method is employed to evaluate crop condition by inter-annual comparisons of both spatial variability (using NDVI images) and seasonal dynamics (based on crop condition profiles). Since this type of method will generate false information if there are changes in crop rotation, cropping area or crop phenology, information on cropped/uncropped arable land is integrated to improve the accuracy of crop condition monitoring. The study proposes a new method to retrieve adjusted NDVI for cropped arable land during the growing season of winter crops by integrating 16-day composite Moderate Resolution Imaging Spectroradiometer (MODIS) reflectance data at 250-m resolution with a cropped and uncropped arable land map derived from the multi-temporal China Environmental Satellite (Huan Jing Satellite) charge-coupled device (HJ-1 CCD) images at 30-m resolution. Using the land map's data on cropped and uncropped arable land, a pixel-based uncropped arable land ratio (UALR) at 250-m resolution was generated. Next, the UALR-adjusted NDVI was produced by assuming that the MODIS reflectance value for each pixel is a linear mixed signal composed of the proportional reflectance of cropped and uncropped arable land. When UALR-adjusted NDVI data are used for crop condition assessment, results are expected to be more accurate, because: (i) pixels with only uncropped arable land are not included in the assessment; and (ii) the adjusted NDVI corrects for interannual variation in cropping area. On the provincial level, crop growing 
profiles based on the two kinds of NDVI data illustrate the difference between the regular and the adjusted NDVI, with the difference depending on the total area of uncropped arable land in the region. The results suggested that the proposed method can be used to improve the assessment of early crop condition, but additional evaluation in other major crop producing regions is needed to better assess the method's application in other regions and agricultural systems.

Keywords: crop condition assessment; cropped and uncropped arable land; North China Plain; NDVI; linear unmixing

\section{Introduction}

The past two decades have seen an increasing demand for timely, transparent and accurate information on global agricultural monitoring for enhancing food security at global, national and sub-national scales. Information about the condition of crops in early crop-growing stages (before harvest) can help indicate potential food surpluses and shortages and support related decision-making [1]. It is essential to facilitate food price stability for agriculture importers and exporters, especially when production shortfalls are anticipated [2]. Several countries and organizations currently employ crop monitoring systems to monitor their own countries' or regional and global crop production $[3,4]$. In the United States, the US Department of Agriculture (USDA) Foreign Agricultural Service (FAS) provides crop monitoring as part of its Global Agricultural Monitoring (GLAM) program [3]. The European Commission operates its AGRI4CAST program implemented by the European Commission Joint Research Center under the Monitoring Agricultural Resources (MARS) program [5-9]. FAO has established the Global Information and Early-Warning System (GIEWS) [10], which focuses on food and agriculture at the global scale. The CropWatch system developed by the Institute of Remote Sensing and Digital Earth (RADI), Chinese Academy of Sciences (CAS), is designed specifically to use remote sensing data to assess national and global crop production and related indicators [4]. The U.S. Agency for International Development (USAID) Famine Early Warning System Network (FEWS-NET) collaborates with international, regional and national partners to provide timely and rigorous early warning and vulnerability information on emerging and evolving food security issues [11]. India operates the Crop Acreage and Production Estimation (CAPE) system [12]. Canada has the Crop Condition Assessment Program (CCAP) [13], and Brazil has the Geosafras program [14].

While a variety of methods are employed, crop condition monitoring is a key component for all these systems [15]. It is particularly important to obtain the crop condition information at an early stage of the crop-growing season, especially for major crop producing and exporting countries [16]. Crop condition in this paper represents the growth status of crops compared with that in a certain reference period [17,18]. In most cases, the crop condition is assessed by using various satellite-derived indices. The normalized difference vegetation index (NDVI), an indicator of the level of photosynthetic activity, reflecting whether the vegetation is stressed or not, is one of the most commonly used indices [1,3,4,11,19-23]. Furthermore, the leaf area index (LAI), the fraction of absorbed photosynthetically active radiation (FAPAR), the temperature condition index (TCI), the vegetation 
condition index (VCI) and the normalized difference water index (NDWI) have been tested for their suitability and validity for crop condition and crop stress monitoring under different environmental conditions around the world [9,24-26]. Based on a multi-year comparison of those various remote sensing-based indices, analysts have combined both current snapshot and seasonal dynamics to evaluate crop conditions and provide information for early crop production evaluation $[1,3,4,22]$.

However, the inter-annual variability of phenology and crop rotation are a major source of uncertainty for crop condition assessment. The result is that information on crop condition variation is mixed with variation in crop phenophase and crop types [27]. Due to the inter-annual variability of crop phenology, crop rotation and cropping area, crop condition monitoring will generate misleading information in the presence of a large change in crop phenology, crop rotation and/or cropping area from the base year to the monitoring year. This is the main source of uncertainty for crop condition monitoring. Accordingly, this paper aims to reduce the uncertainty caused by changes in crop rotation and cropping area by integrating high spatial resolution multi-temporal China Environmental Satellite (Huan Jing Satellite, HJ-1) charged-coupled device (CCD) images and time series MODIS NDVI products. A method is proposed to generate an adjusted NDVI using an uncropped arable land ratio (UALR). Crop condition assessments (both current snapshots and seasonal dynamics) are compared with and without the use of the proposed method.

\section{Data and Study Area}

\subsection{Site Description}

The study area, on the North China Plain (NCP), one of China's major grain producing regions, extends from $32^{\circ} 00^{\prime} \mathrm{N}$ to $40^{\circ} 24^{\prime} \mathrm{N}$ and $112^{\circ} 48^{\prime} \mathrm{E}$ to $122^{\circ} 45^{\prime} \mathrm{E}$, an area of approximately $310,000 \mathrm{~km}^{2}$ (Figure 1). Seven mega-cities/provinces are situated on the NCP (Beijing, Tianjin and parts of Hebei, Shandong, Henan, Anhui and Jiangsu provinces). The mean annual precipitation ranges between 480 and $1050 \mathrm{~mm}$, concentrated between June and September during the summer monsoon [28]. According to Generic Soil Classification of China and Soil Taxonomy, Inceptisols dominate the North China Plain [29]. The plain has very diverse climatic conditions, from a cold, arid steppe regime to a humid, warm temperate regime with hot summers according to the data derived from the FAO New_LocClim database [30] (Table 1). Most of the region belongs to the warm temperate climatic zone. Farming practices and rain-fed production potential vary accordingly. Multiple cropping systems are mainly practiced in southern portions of the NCP; central areas are generally dominated by the rotation of winter wheat and maize and the relay intercropping of winter wheat and cotton; and northern areas mainly practice a single cropping system, because of the cold climate and short frost-free period [31]. Spring maize and cotton are the main crops in areas with a one-crop-a-year system. The study area is characterized by the cultivation of wheat, maize, rice, cotton, groundnut, soybean, vegetables and other small crops in farms subdivided into very small parcels belonging to multiple families [27,32]. Figure 2, based on data provided by the China Meteorological Administration (CMA), shows crop phenology for five major crops on the NCP. 
Figure 1. Location of the study area. The images are HJ-1 CCD images.

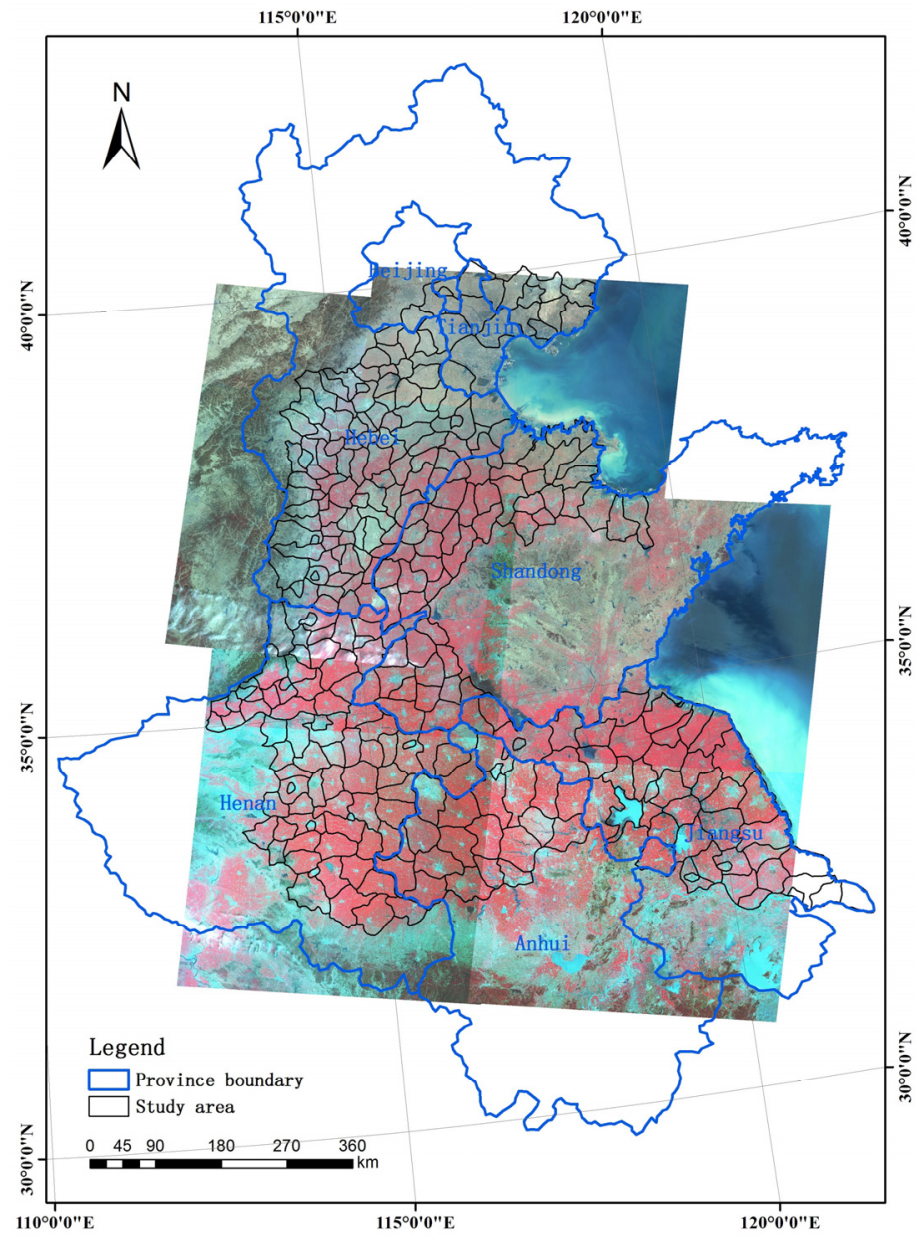

Table 1. Climatic characteristics of the North China Plain (NCP) area.

\begin{tabular}{|c|c|c|c|c|c|c|c|}
\hline Items & Anhui & Beijing & Hebei & Henan & Jiangsu & Shandong & Tianjin \\
\hline Longitude (Degree) * & 116.66 & 116.56 & 115.87 & 114.73 & 119.27 & 116.56 & 117.37 \\
\hline Latitude (Degree) * & 33.41 & 39.72 & 38.41 & 34.27 & 33.56 & 36.91 & 39.31 \\
\hline Altitude (m) & 20 & 20 & 0 & 40 & 0 & 0 & 0 \\
\hline Kōppen climate class & BSk & Dwa & $\mathrm{BSk}$ & Cwa & Cwa & BSk & Dwa \\
\hline $\begin{array}{l}\text { Kōppen Climate } \\
\text { description }\end{array}$ & $\begin{array}{l}\text { Cold arid } \\
\text { steppe } \\
\text { climate }\end{array}$ & $\begin{array}{l}\text { Snow climate } \\
\text { with dry } \\
\text { winter and hot } \\
\text { summer }\end{array}$ & $\begin{array}{l}\text { Cold arid } \\
\text { steppe } \\
\text { climate }\end{array}$ & $\begin{array}{l}\text { Warm } \\
\text { temperate with } \\
\text { dry winter and } \\
\text { hot summer }\end{array}$ & $\begin{array}{l}\text { Warm } \\
\text { temperate with } \\
\text { dry winter and } \\
\text { hot summer }\end{array}$ & $\begin{array}{l}\text { Cold arid } \\
\text { steppe } \\
\text { climate }\end{array}$ & $\begin{array}{l}\text { Snow climate } \\
\text { with dry } \\
\text { winter and hot } \\
\text { summer }\end{array}$ \\
\hline $\begin{array}{l}\text { Budyko radiation } \\
\text { dryness }\end{array}$ & 2.574 & 1.881 & 2.932 & 1.615 & 1.299 & 2.653 & 2.001 \\
\hline Budyko runoff (\%) & 5.9 & 11.5 & 4.1 & 15.3 & 21.6 & 5.5 & 10.2 \\
\hline $\begin{array}{l}\text { Gorczynski } \\
\text { Continentality }\end{array}$ & 62.7 & 59.9 & 68.8 & 59.0 & 60.2 & 60.6 & 60.9 \\
\hline $\begin{array}{l}\text { Miami model rainfed } \\
\text { NPP }\left(g(D M) / \mathrm{m}^{2} / \text { year }\right)\end{array}$ & 807 & 962 & 677 & 1,173 & 1,377 & 772 & 934 \\
\hline
\end{tabular}

Data are derived from the FAO New_LocClim database [30]. * These coordinates are the centroid of the intersection area of the NCP and each administrative boundary. Climate features were calculated at each coordinate. 
Figure 2. Crop calendars for North China Plain (NCP) areas.

\begin{tabular}{|c|c|c|c|c|c|c|c|c|c|c|c|c|}
\hline & Jan & Feb & Mar & Apr & May & Jun & Jul & Aug & Sep & Oct & Nov & Dec \\
\hline \multicolumn{13}{|l|}{ Winter wheat } \\
\hline \multicolumn{13}{|l|}{$\begin{array}{c}\text { Summer } \\
\text { maize }\end{array}$} \\
\hline \multicolumn{13}{|l|}{ Cotton } \\
\hline \multicolumn{13}{|l|}{ Spring maize } \\
\hline \multicolumn{13}{|l|}{ Soybean } \\
\hline & & & & & & & & & & & & \\
\hline & & & owing & & & Growi & & & Harv & ting & & \\
\hline
\end{tabular}

\subsection{Field Survey}

Ground surveys were carried out from 25 April to 2 May 2010, and 23 April to 3 May 2011. A handheld global positioning system (GPS) from Unistrong Science \& Technology Co., Ltd, Beijing, China, with a positional accuracy of $<5 \mathrm{~m}$, was used to record the boundary of sampled fields. Based on the field surveys, samples for two classes, namely cropped and uncropped arable land, were obtained. Half of the samples were randomly selected as training samples, and the remaining half were used for the classification accuracy evaluation. The training and validation samples had no overlap.

\subsection{Remote Sensing Data}

The China Environment Satellite is an Earth observation, small satellite constellation containing three satellites (HJ-1A, HJ-1B and HJ-1C) for environment and disaster monitoring. The technical specifications of the on-board cameras on the HJ-1A and HJ-1B satellites are listed in Table 2. Images and orbital characteristics are available on the web page of the China Centre for Resources Satellite Data and Applications (CRESDA) [33].

Table 2. Characteristics of HJ-1B onboard sensors.

\begin{tabular}{|c|c|c|c|c|c|}
\hline Satellite & Sensor & Channels $(\mu \mathrm{m})$ & Spatial Resolution (m) & Swath Width (km) & Revisit Period \\
\hline \multirow{5}{*}{ HJ-1A } & \multirow{4}{*}{$\begin{array}{l}\text { Charge-coupled } \\
\text { device (CCD) } \\
\text { camera }\end{array}$} & B $0.43-0.52$ & 30 & \multirow{4}{*}{360} & \multirow{13}{*}{ Four days } \\
\hline & & $G 0.52-0.60$ & 30 & & \\
\hline & & $R 0.63-0.69$ & 30 & & \\
\hline & & $N I R_{C C D} 0.76-0.90$ & 30 & & \\
\hline & $\begin{array}{l}\text { Hyperspectral } \\
\text { imager }\end{array}$ & $\begin{array}{l}0.45-0.95 \\
(110-128 \text { bands })\end{array}$ & 100 & 50 & \\
\hline \multirow{8}{*}{ HJ-1B } & \multirow{4}{*}{$\begin{array}{l}\text { Charge-coupled } \\
\text { device }(\mathrm{CCD}) \\
\text { camera }\end{array}$} & B $0.43-0.52$ & 30 & \multirow{4}{*}{360} & \\
\hline & & $G 0.52-0.60$ & 30 & & \\
\hline & & $R 0.63-0.69$ & 30 & & \\
\hline & & $N I R_{C C D} 0.76-0.90$ & 30 & & \\
\hline & \multirow{4}{*}{ IRS camera } & $N I R_{I R S} 0.75-1.10$ & 150 & \multirow{4}{*}{720} & \\
\hline & & SWIR $1.55-1.75$ & 150 & & \\
\hline & & TIR1 3.50-3.90 & 150 & & \\
\hline & & TIR2 10.5-12.5 & 300 & & \\
\hline
\end{tabular}


HJ-1A/B charge-coupled device (CCD) images were acquired for late-March and early May for both 2010 and 2011 based on the winter crop phenology. Seven images were needed to cover the whole study area, and a total of 28 cloudless images were collected. Image processing, which included geo-correction, radiance calibration and atmospheric correction, used the ENVI 4.8 software. An average root mean square error (RMSE) of 0.87 pixels was achieved for these images. NDVI images for each CCD image were generated and mosaicked into a single CCD NDVI image for the entire study area. Based on the acquisition dates, a total of four CCD NDVI images for the NCP study area were generated for late-March and early May in 2010 and 2011.

Time series of 16-day composite MODIS NDVI products and reflectance products from Terra and Aqua satellites at 250-m resolution were acquired for October to June for both 2010 and 2011 using NASA's Reverb tool [34]. Five tiles (h26v04, h26v05, h27v04, h27v05 and h28v05) were used for crop condition assessment.

\subsection{Auxiliary Data}

A land-cover map for 2010 at a scale of 1:100,000, derived from HJ-1 CCD images [35], was used to separate arable from non-arable land. This vector database was clipped to provincial boundaries.

\section{Method}

\subsection{Uncropped Arable Land Ratio (UALR) Derivation}

The first step for UALR calculation is the separation of cropped fields and uncropped fields over the arable land fields. Arable land was extracted using the 2010 land-cover map. Over the arable land, the differences in the CCD NDVI between late-March and early May were calculated for both 2010 and 2011, and cumulative frequency histograms of these differences were constructed for the training samples for both years. We tried to acquire cloudless images, but there were still a few cloudlets in some of the images. In order to reduce the impact of unfavorable weather conditions, an initial NDVI threshold value of 0.4 for early May was used to identify cropped land. According to the winter crop phenology, winter crops are at the growing peak in early May, while bare soil or only sparse weeds can be observed over uncropped arable land. Otherwise, a threshold for the differences in the CCD NDVI between late-March and early May was used to separate cropped and uncropped arable land fields. The maximum difference in NDVI over the training samples was not taken as the CCD NDVI difference threshold, because of the noise in NDVI images [36,37]. In this paper, we found that when the threshold was set as $98 \%$ cumulative frequency of NDVI differences, the highest identification accuracy of cropped and uncropped arable fields can be achieved. A similar method was used to extract maximum or minimum NDVI for each biome [37-40]. The corresponding decision tree used to identify cropped and uncropped arable land fields is shown in Figure 3.

The accuracy evaluation of the cropped and uncropped arable land maps was based on the independent validation samples. To evaluate the classification results, classification accuracy measures (including the producer's accuracy, the user's accuracy for each type and the overall accuracy) and kappa statistics estimated from the confusion matrix were used [41]. 
Figure 3. The decision tree for cropped and uncropped arable land mapping.

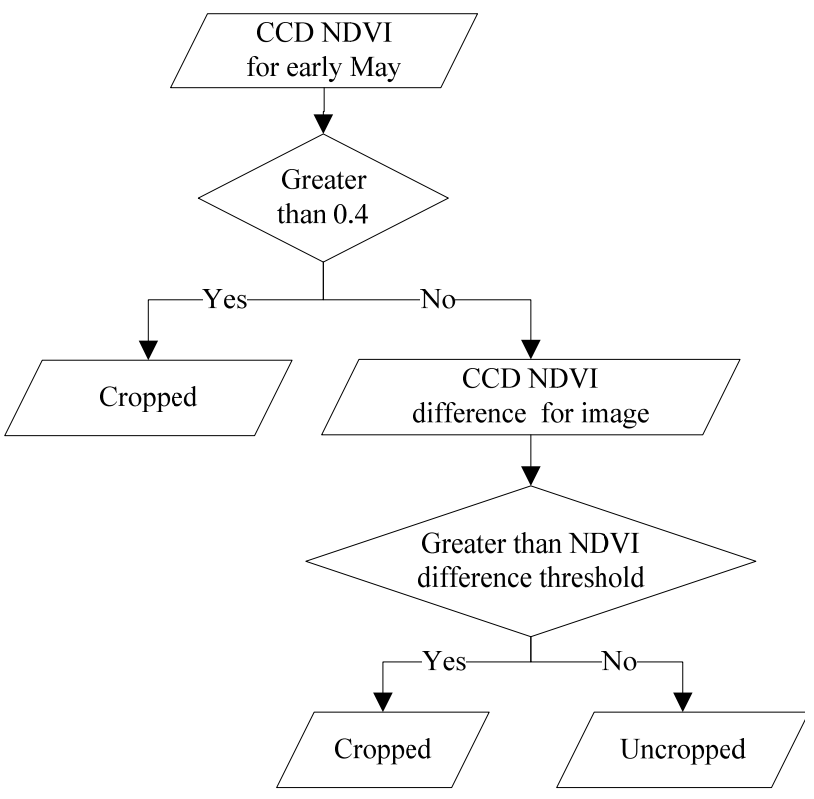

To generate the UALR map, the cropped/uncropped distribution map was resampled to a $250-\mathrm{m}$ resolution using the nearest neighbor resample method. The values for each $250-\mathrm{m}$ pixel were obtained by counting the number of uncropped (Nuc) and cropped $(\mathrm{Nc}$ ) pixels at $30-\mathrm{m}$ resolution located in each $250-\mathrm{m}$ pixel. The uncropped arable land ratio (UALR) for each pixel was calculated using the equation:

$$
\mathrm{UALR}=\frac{\mathrm{N}_{\mathrm{uc}}}{\mathrm{N}_{\mathrm{uc}}+\mathrm{N}_{\mathrm{c}}}
$$

UALR was assumed to be stable during the growing season.

\subsection{Linear Spectral Unmixing Using UALR}

For the MODIS images, each pixel was considered as a mixture of two endmembers, namely cropped and uncropped arable land. It was assumed that reflectance of cropped arable land and uncropped arable land is linearly mixed based on the proportions of each type. Only red band and near-infrared band reflectance was used for the spectral unmixing analysis. The red band and near-infrared band reflectance of cropped arable land for each pixel was found by solving the equations:

$$
\left\{\begin{array}{c}
\rho_{\mathrm{R}}=\rho_{\mathrm{R}_{\text {cropped }}} *(1-\mathrm{UALR})+\rho_{\mathrm{R}_{\text {uncropped }}} * \text { UALR } \\
\rho_{\mathrm{NIR}}=\rho_{\mathrm{NIR}_{\text {cropped }}} *(1-\mathrm{UALR})+\rho_{\mathrm{NIR}_{\text {uncropped }}} * \text { UALR }
\end{array}\right.
$$

where $\rho_{R}$ and $\rho_{N I R}$ are the reflectance of the red band and near-infrared band in a given MODIS pixel, UALR is the ratio of uncropped arable land in the pixel and $\rho_{\text {Rcropped }} / \rho_{\text {NIRcropped }}$ and $\rho_{\text {Runcropped }} / \rho_{\text {NIRuncropped }}$ are the red band and near-infrared band reflectance of the endmembers. The average reflectance for red and near-infrared bands at each acquisition date of MODIS was calculated over the pixels for which UALR was higher than $98 \%$ to represent $\rho_{\text {Runcropped }} / \rho_{\text {NIRuncropped. Since }}$ Inceptisols is the dominant soil order in the North China Plain [29], it is assumed that the band reflectance of uncropped arable land is relatively constant throughout the study area. 
Using Equation (3), $\rho_{\text {Rcropped }}$ and $\rho_{\text {NIRcropped }}$ can be derived as follows:

$$
\left\{\begin{array}{c}
\rho_{\mathrm{R}_{\text {cropped }}}=\frac{\rho_{\mathrm{R}}-\rho_{\mathrm{R}_{\text {uncropped }} * \text { UALR }}}{1-\text { UALR }} \\
\rho_{\mathrm{NIR}_{\text {cropped }}}=\frac{\rho_{\mathrm{NIR}}-\rho_{\mathrm{NIR}_{\text {uncropped }} * \mathrm{UALR}}}{1-\mathrm{UALR}}
\end{array}\right.
$$

NDVI values of pure cropped arable land (UALR-adjusted NDVI) for each pixel can then be derived using $\rho_{\text {Rcropped }}$ and $\rho_{\text {NIRcropped }}$ in Equation (3), as well as the following equation:

$$
\text { UALR adjusted NDVI }=\mathrm{NDVI}_{\text {cropped }}=\frac{\rho_{\mathrm{NIR}_{\text {cropped }}}-\rho_{\mathrm{R}_{\text {cropped }}}}{\rho_{\mathrm{NIR}_{\text {cropped }}}+\rho_{\mathrm{R}_{\text {cropped }}}}
$$

\subsection{Crop Condition Monitoring Method}

Based on the NDVI purification method described in Section 3.2, the UALR-adjusted NDVI time series derived from the 16-day composite MODIS band reflectance data were used for crop condition assessment. Inter-annual comparisons of UALR-adjusted NDVI for corresponding time periods and the seasonal dynamics of the UALR-adjusted NDVI time series (the NDVI profile) were employed for crop condition monitoring [1]. NDVI profiles were developed based on the statistical average of UALR-adjusted NDVI in a particular region.

For current snapshots, two NDVI images representing comparable periods from the current and previous years are compared to identify areas where crop conditions are worse, better or similar/normal [17,18]. In the paper, for each pixel, crop condition is defined as worse if the NDVI difference between the current and previous years is lower than -0.075 , while a better crop condition represents pixels with NDVI difference between the current and previous years larger than 0.075. Otherwise, crop condition is at the normal level. Below the normal crop condition (worse or slightly worse condition) indicates decreases of spatial greenness in the monitoring period compared with the reference period, which relates to unhealthy crop, drought effects and a smaller area under crop. The better crop condition represents increases of spatial greenness over time, which relates to better environmental conditions, better crop management and more cropping areas. The inter-annual comparison can pinpoint areas with abnormal conditions. For seasonal dynamics, a time series of NDVI images across the growing season is used to develop crop-growth profiles based on the statistical average of the NDVI (weighted for the percentage of farmland) in a region or country compared to those from previous years $[16,22,42]$. The process uses counties as the basic unit for the extraction and reconstruction of crop-growth profiles. The crop condition results of both assessments - the current snapshot and the seasonal dynamic - are combined with information about phenol-phase, agro-meteorological conditions and variations in the crop proportion for a comprehensive analysis and assessment of the crop condition [4].

\section{Results}

\subsection{Cropped and Uncropped Arable Land Mapping and Accuracy Evaluation}

Figure 4 is a cropped and uncropped arable land distribution map of the study area in 2010 and 2011. Uncropped arable land is very unevenly distributed. A total of $16.6 \%$ and $18.3 \%$ of the arable 
land over the study area were uncropped in the winter crop growing season in 2010 and 2011, respectively. Most of the uncropped arable land is located in the north of the study region, specifically in Hebei and Shandong provinces. More uncropped arable land was observed along the west coast areas of Bohai Bay in 2011 than 2010, while less arable land was uncropped in southern Hebei in 2011 than 2010. Uncropped arable land during the winter crop growing season in southern Hebei and the neighboring areas in Shandong (red circle in Figure 4) was mainly kept for cotton and ground nut (single cropping system) cultivation during the summer. Salinization and alkalization of farmland soil are the major problems for the crops in the west coastal region of Bohai Gulf [43]. The uncropped arable land area expanded in 2011 compared to 2010 in the Yellow River delta. Only a small percentage of arable land in Henan, Anhui and Jiangsu provinces was uncropped for both 2010 and 2011.

Figure 4. The distribution of cropped and uncropped arable land for the winter crop growing season in NCP in 2010 (a) and 2011; (b) using HJ-1 CCD images.

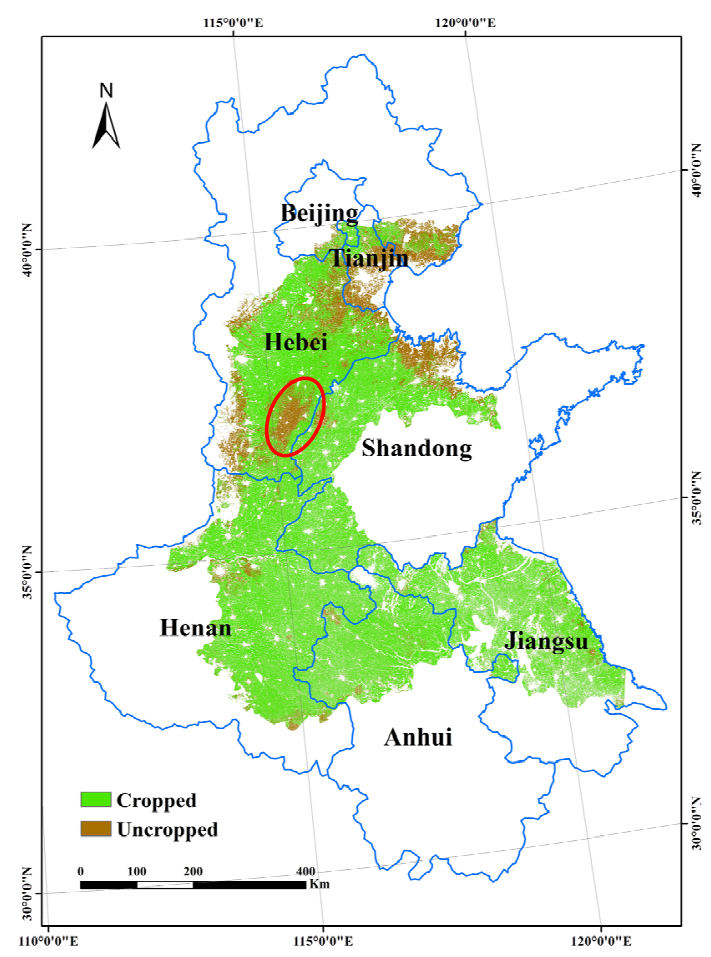

(a)

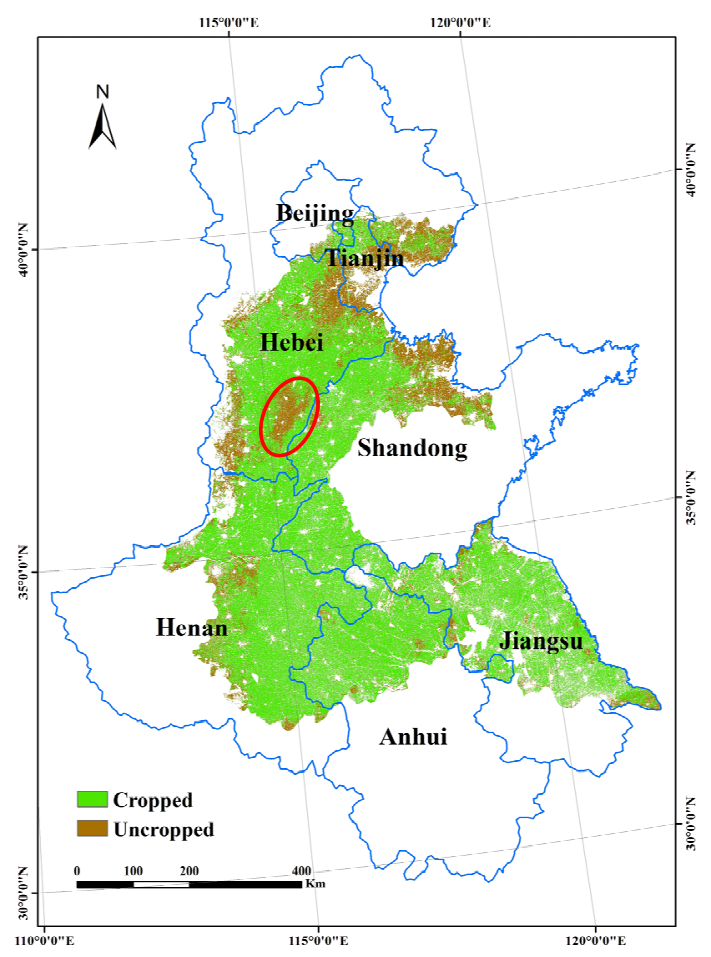

(b)

The error matrix and classification accuracy for cropped and uncropped arable land in 2010 and 2011 is shown in Tables 3 and 4. Both producer's and user's accuracy exceeded 97\% in the two years, except for a user's accuracy of $92.91 \%$ for the "cropped" type in 2010 . The overall classification accuracy was $97.81 \%$ for 2010 and $99.85 \%$ for 2011 ; the kappa coefficients were 0.9485 and 0.9810 , which signifies that the classified cropped and uncropped arable land map was in agreement with the ground-truth data. As shown in Table 3, about 3\% of uncropped pixels verified on the ground were misclassified as cropped, whereas almost $7 \%$ of cropped pixels were misclassified as uncropped pixels in 2010. For 2011, both omission and commission errors were less than $3 \%$ for uncropped and cropped. The commission error for cropped in 2010 was higher mainly due to cloudy conditions on some images. Misclassified pixels usually occurred at the intersection of different HJ-1 CCD images. 
Table 3. Error matrix and accuracy for 2010 cropped/uncropped map.

\begin{tabular}{cccc}
\hline Ground-Truth & \multicolumn{2}{c}{ Classified Category (Pixels) } & \multirow{2}{*}{ Producer's Accuracy } \\
\cline { 2 - 3 } Category(pixels) & Uncropped & Cropped & \\
\hline Uncropped & 47,638 & 1341 & $97.26 \%$ \\
Cropped & 116 & 17,577 & $99.34 \%$ \\
User's Accuracy & $99.76 \%$ & $92.91 \%$ & \\
\hline
\end{tabular}

Table 4. Error matrix and accuracy for 2011 cropped/uncropped map.

\begin{tabular}{cccc}
\hline \multirow{2}{*}{ Ground-Truth Category(Pixels) } & \multicolumn{2}{c}{ Classified Category (Pixels) } & \multirow{2}{*}{ Producer's Accuracy } \\
\cline { 2 - 3 } & Uncropped & Cropped & \\
\hline Uncropped & 47,832 & 389 & $99.19 \%$ \\
Cropped & 73 & 16,067 & $99.55 \%$ \\
User's Accuracy & $99.85 \%$ & $97.64 \%$ & \\
\hline
\end{tabular}

\subsection{Uncropped Arable Land Ratio}

Figure 5 shows the 250-m resolution UALR maps for the winter crop growing season. Obviously, the distribution of UALR has the same spatial pattern as uncropped arable land. UALR in 2011 was higher than in 2010 in the west coastal areas of Bohai Bay and the Yellow River delta. Furthermore, a larger UALR in western Henan province was observed in 2011 than 2010, though the ratio value was relatively low compared with regions, such as the Yellow River delta.

Figure 5. Uncropped arable land ratio (UALR) map for the winter crop growing season in NCP in 2010 (a) and 2011 (b).

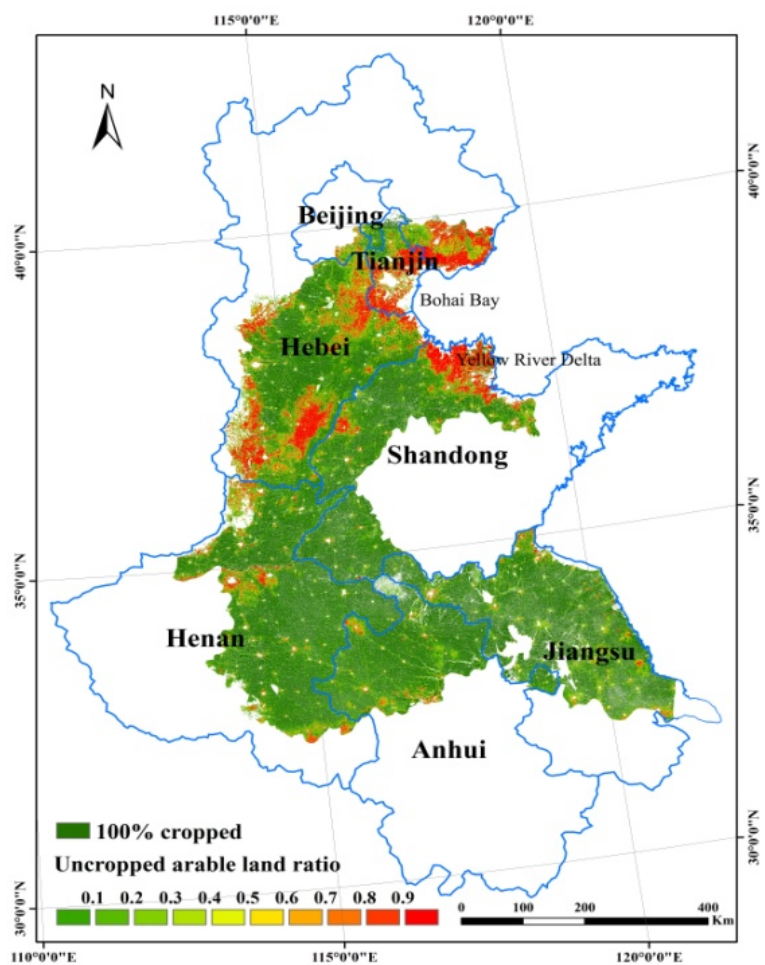

(a)

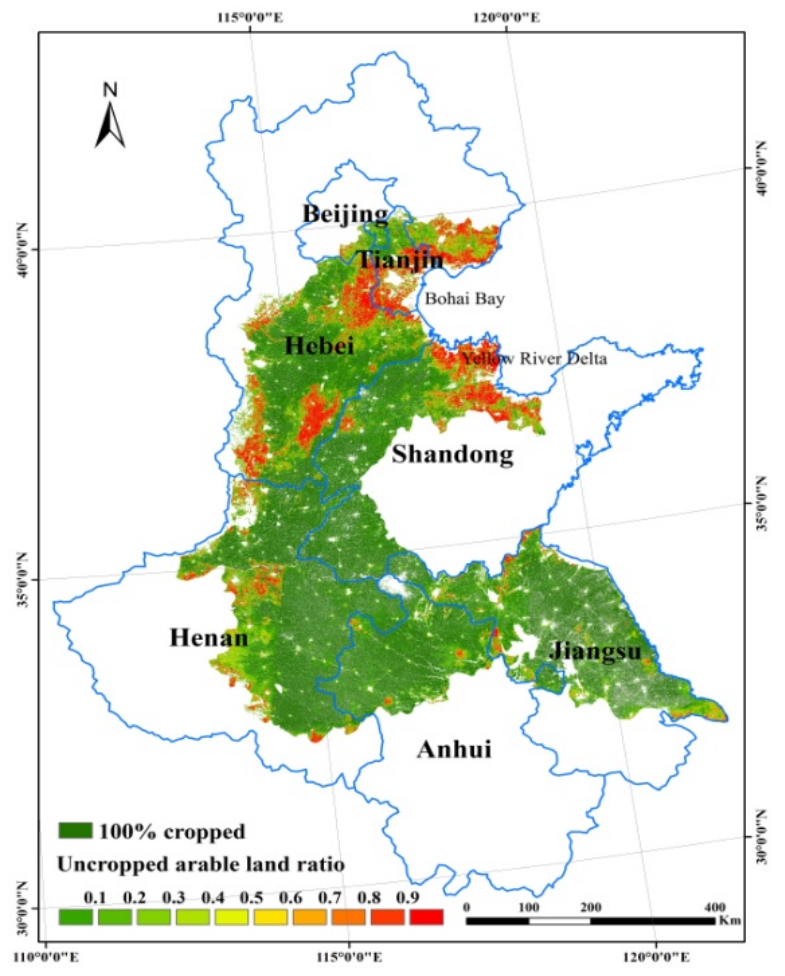

(b) 


\subsection{UALR-Adjusted NDVI vs. MODIS NDVI}

A linear unmixing technique was applied to the red and NIR band reflectance for MODIS using UALR to generate endmember band reflectance for cropped arable land. UALR-adjusted NDVI was then calculated over the study area from January to June 2010 and 2011. Pixels with a UALR greater than 0.98 were marked as uncropped pixels. MODIS NDVI and UALR-adjusted NDVI values over the regions where UALR was lower than 0.98 were averaged and compared. Figure 6 shows the relationship between MODIS NDVI and UALR-adjusted NDVI. Each point in Figure 6 represents average NDVI at a different acquisition date. Clearly, MODIS NDVI is strongly correlated with UALR-adjusted NDVI $\left(R^{2}>0.99\right.$ for both 2010 and 2011), and the intercept of the regression line for both years is very close to zero. After the UALR correction, UALR-adjusted NDVI is larger than the MODIS NDVI.

Figure 7 shows the combined histograms for the 16-day combination MODIS NDVI from the 153rd to the 168th day of 2011 and the UALR-adjusted NDVI. A positive non-zero skew is apparent in both data sets, with the skewness value for the UALR-adjusted NDVI larger than for the MODIS NDVI. The spatial average UALR-adjusted NDVI (0.3922) was $2.5 \%$ higher than the average MODIS NDVI (0.3827). A scatter plot of all valid NDVI pixels for the MODIS NDVI and UALR-adjusted NDVI is shown in Figure 8. Different colors represented different pixel densities. Most of the pixels are located along the 1:1 line, and the $R^{2}$ between the MODIS NDVI and UALR-adjusted NDVI is 0.989 .

Figure 6. Relationship between spatially-averaged MODIS NDVI and UALR-adjusted NDVI for 2010 and 2011.

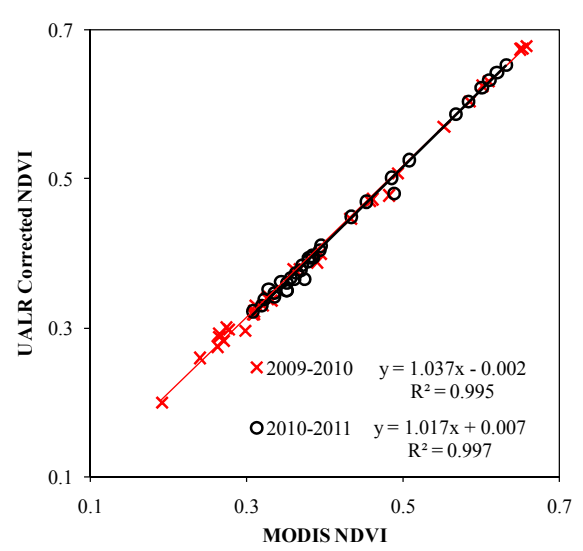

Figure 7. The frequency distribution of MODIS NDVI and UALR-adjusted NDVI for early June 2011.

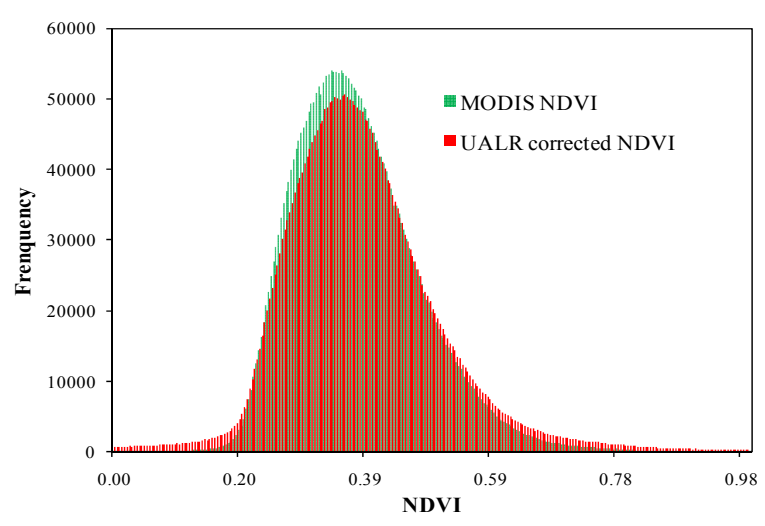


Figure 8. The scatter plot of all valid pixels for MODIS NDVI and UALR-adjusted NDVI for early June 2011.

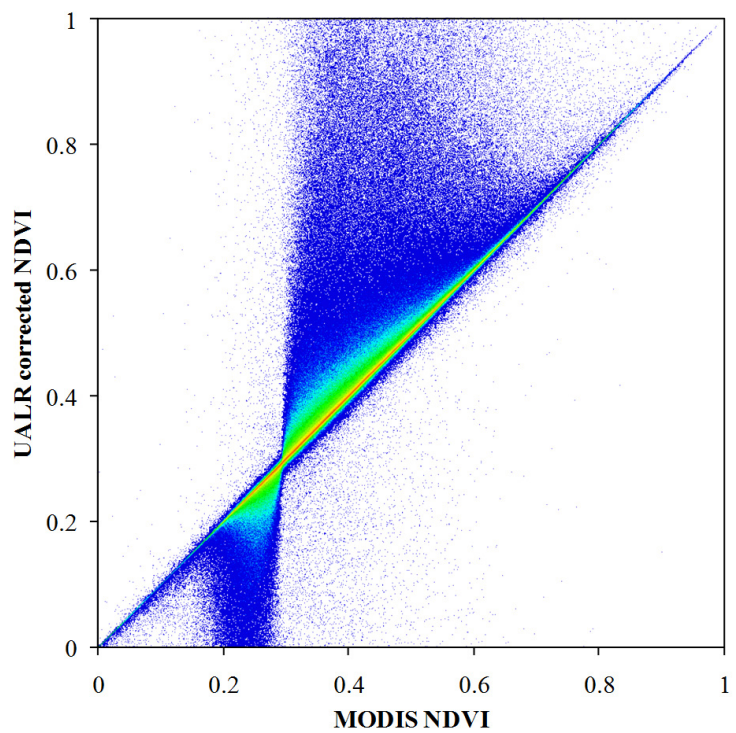

\subsection{Crop Condition Assessment Result}

Figure 9 shows the spatial heterogeneity of crop conditions over the NCP study area for early May 2011, compared to the previous year. Figure 9a was generated from the 16-day composite MODIS NDVI data for Julian Days 153 to 168, while Figure 9b was produced from the UALR-adjusted NDVI over the same period. The color coding in the two crop condition maps is the same, except for an additional gray color in Figure 9b representing uncropped arable land. (As discussed above, pixels with a UALR larger than 0.98 in either 2010 or 2011 were excluded and are marked as this additional class in Figure 9b.) Overall, the two maps show similar spatial patterns. Generally, crop condition in the study area in early May 2011, was not as good as 2010. However, crop condition is better in 2011 compared with 2010 in central and northern parts of the study area; poorer condition crops are mostly situated in southern sections. The southernmost part of Henan province, northwest Anhui province and the peripheral areas of Jiangsu province have the worst crop conditions as a result of excessive rainfall and a lack of radiation in 2011. Better crop conditions are observed in the neighboring regions of Zhengzhou and Shijiazhuang, the capitals of Henan and Hebei provinces, respectively.

Although similar overall, there are some differences in the detail between the two maps. Statistically, for the MODIS NDVI data, $8 \%$ of cropland shows a better condition (dark and light green areas) in early May 2011, compared with 2010, and 9.2\% is worse (red and orange-red regions), while the rest maintained a similar condition (yellow-green areas). For the UALR-adjusted NDVI data, $13.4 \%$ of cropped land shows a better condition and $14.3 \%$ a worse condition. Crop conditions in the southern NCP are noticeably poorer in Figure 9b than that in Figure 9a. This is consistent with the UALR distribution map. Southern NCP (especially south of Henan and north of Anhui) kept more arable land uncropped during the winter crop growing season in 2010 than in 2011. In the neighboring areas of northernmost Henan province and southernmost Hebei province, crop condition was generally normal in 2011 compared with 2010 based on MODIS NDVI data (Figure 9a), while a poor crop condition is observed from the UALR-adjusted NDVI data (Figure 9b). 
Figure 9. Crop condition map of NCP using MODIS NDVI (a) and UALR-adjusted NDVI; (b) for early May 2011. The maps show the condition of the crop compared to the previous year.

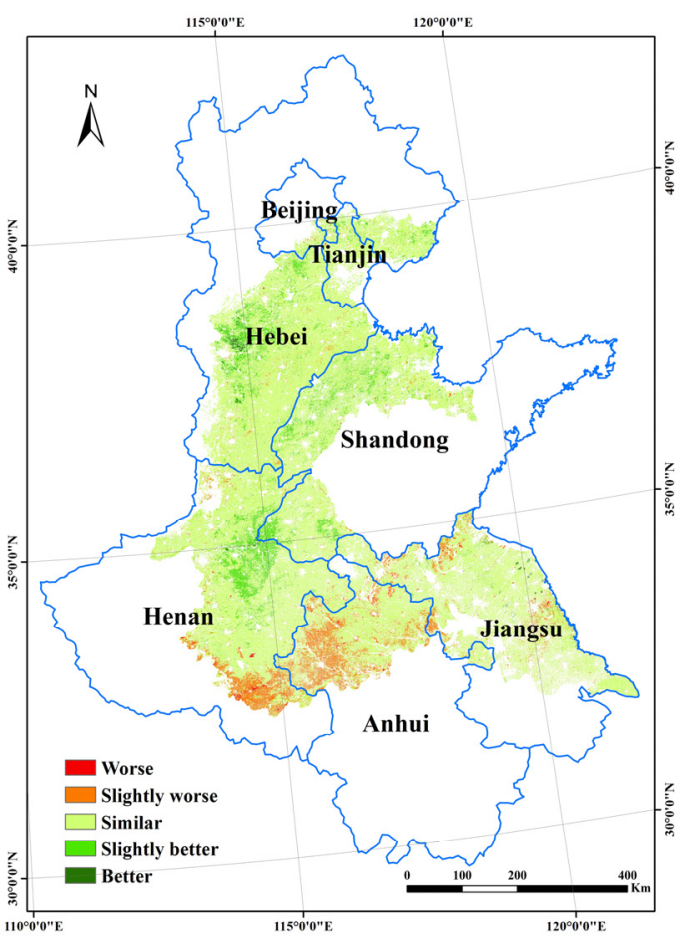

(a)

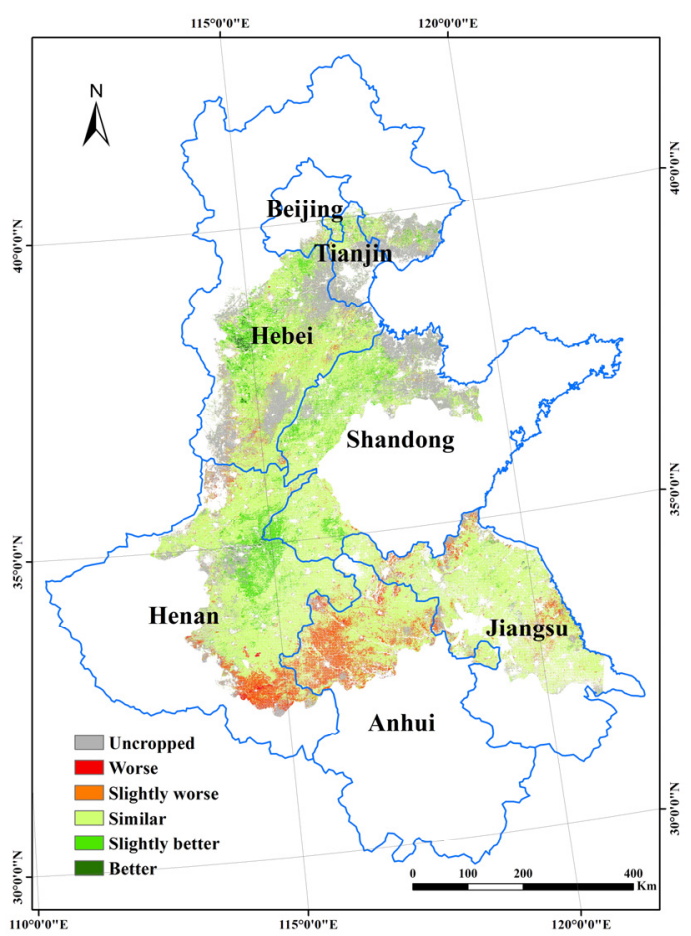

(b)

The crop growth profiles for the study area also confirm the poorer crop condition in 2011 compared to 2010 (Figure 10). The spatial average MODIS NDVI during the winter crop growing season ranged from 0.19 to 0.66 for $2009-2010$ and from 0.31 to 0.63 for 2010-2011. The corresponding UALR-adjusted NDVI ranged from 0.20 to 0.68 and from 0.32 to 0.65 . The lowest NDVI occurs in winter when crops are dormant, and the peak NDVI occurs in early May when winter wheat is flowering. The peak NDVI during the 2010-2011 winter crop growing season was 4.4\% lower than that during the 2009-2010 growing season, while the lowest average NDVI was much higher in 2010-2011 than in 2009-2010. The main reason was the amount of snow fall during winter in 2010-2011, which was much less than during 2009-2010. Most of the crops in the north portions of the study area during winter 2009-2010 were covered by snow, which has a much lower NDVI than dormant crops.

Figure 10 shows crop growth profiles based on MODIS NDVI data (green and purple lines) and UALR-adjusted NDVI data (blue and red lines) for the NCP overall and for five separate provinces in the NCP. The provincial charts show distinctive characteristics deriving from the impact of differences in topography and climate on crop phenology and growth patterns in different regions. The overall profile for the NCP is an amalgam of these differences. For example, two sudden drops are apparent in the overall NCP 2009-2010 profiles (blue and green lines), the first in early November 2009, and the second in early February 2010. These drops are a reflection of the NDVI profiles for the five provinces. Henan province suffered from both unseasonable snow fall in early November 2009 and rainfall in early February 2010, which is reflected by the two drops in its profile. Anhui and Jiangsu were 
affected by the rainfall in early February 2010, while Hebei and Shandong suffered from heavy snow in early November 2009, which is reflected in single drops in their profiles. However, all of the growth profiles have some similar basic patterns. Average UALR-adjusted NDVI values are all higher to some degree than average MODIS NDVI. Furthermore, winter crop phenology in the 2010-2011 growing season was around ten days ahead compared with 2009-2010 due to the dry and warmer winter in 2010-2011, significantly more so for Shandong, Hebei and Henan provinces. Crop growth profiles for Jiangsu and Anhui provinces for 2010-2011 were well below that of 2009-2010, because of severe drought throughout the growing season. For example, for Anhui, the peak of UALR-adjusted NDVI in the 2010-2011 winter growing season was 5.5\% lower and the peak of MODIS NDVI was 6\% lower than in 2009-2010. The peak of MODIS NDVI and UALR-adjusted NDVI for other provinces also differ significantly.

Figure 10. Crop growth profiles for North China Plain (a) and five provinces: Anhui (b), Hebei (c), Henan (d), Jiangsu (e) and Shandong (f).
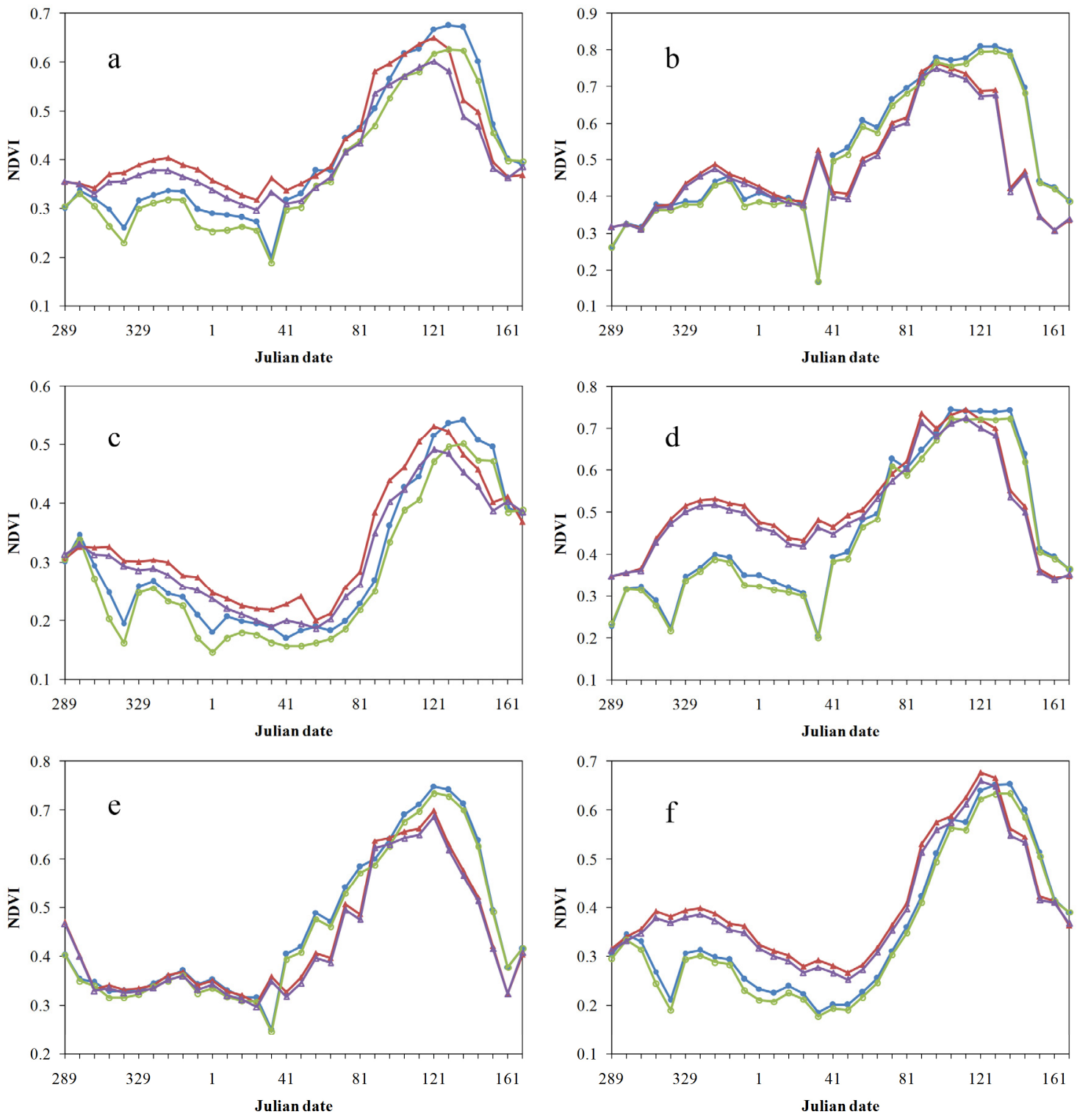

$\rightarrow$ 2009-2010 adjusted $\rightarrow 2009-2010$

$\quad-2009-2010$ adjusted $\quad \leq 2010-2011$ 


\section{Discussion}

\subsection{Highlighted Difference by Using UALR-Adjusted NDVI and MODIS NDVI}

The UALR-adjusted NDVI, which incorporates uncropped arable land information, should be used for crop condition assessment rather than the original MODIS NDVI. It generates more accurate crop condition estimates, since it eliminates the influence of inter-annual variability in arable land utilization. The article proposes a method for obtaining NDVI that is adjusted for the fact that parts of a pixel may not be cropped in one year, but may be cropped in another year; adjusting for this difference and then using this UALR-adjusted NDVI for crop monitoring will, by definition, yield more accurate monitoring results, simply by removing the variance in NDVI that is caused by the change in crop area, not crop condition. The UALR-adjusted NDVI then is a more accurate measure of the real crop condition.

As is shown in Figure 11, uncropped arable land area (b) was much less than that in 2010 (a). Using MODIS NDVI, normal crop condition dominated the area in Figure 11. However, the more cropping areas in 2011 contributed to the normal crop condition. Actually, the greenness of the cropped area in 2011 was lower than that in 2010. As a result, nearly half of the area in Figure 11d was recognized as in worse condition using UALR-adjusted NDVI.

Figure 11. Crop monitoring using UALR-adjusted NDVI vs. MODIS NDVI. (a) Cropped and uncropped map in 2010; (b) cropped and uncropped map in 2011; (c) crop condition using MODIS NDVI; (d) crop condition using UALR-adjusted NDVI.

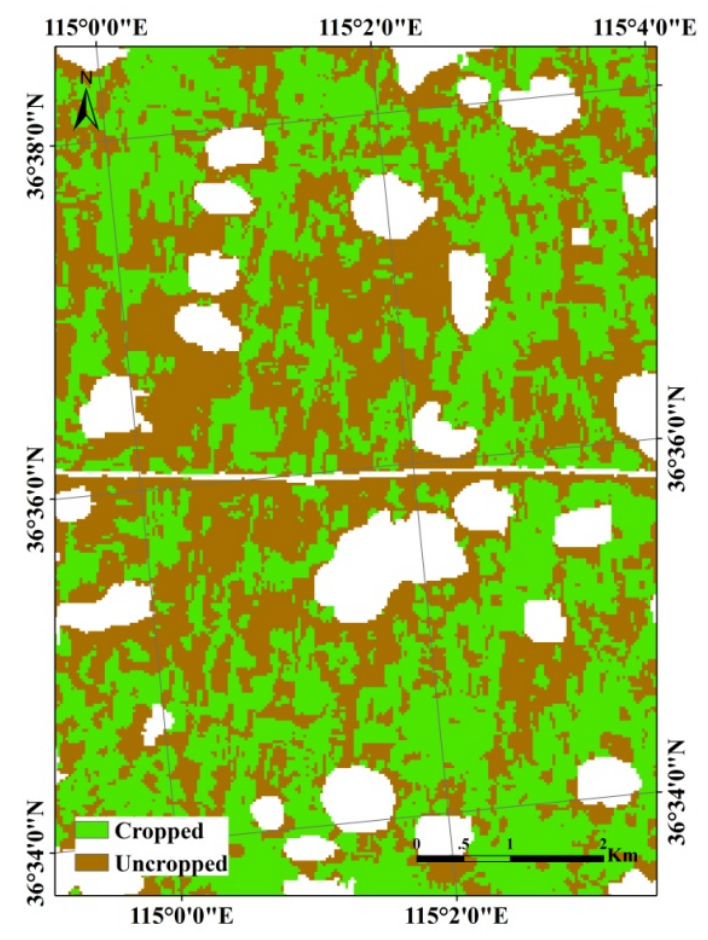

(a)

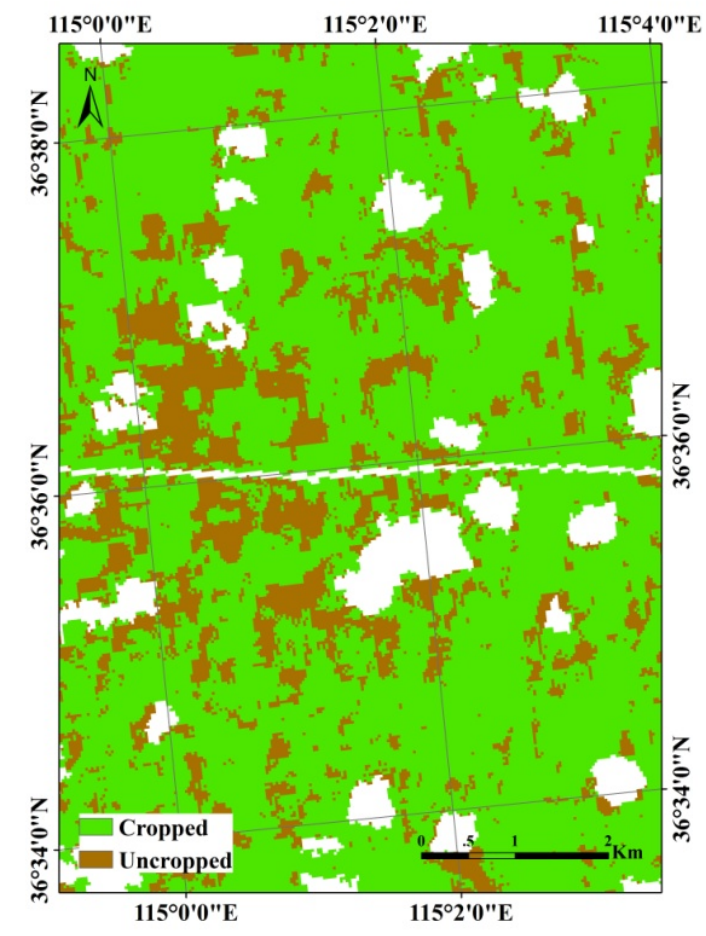

(b) 
Figure 11. Cont.

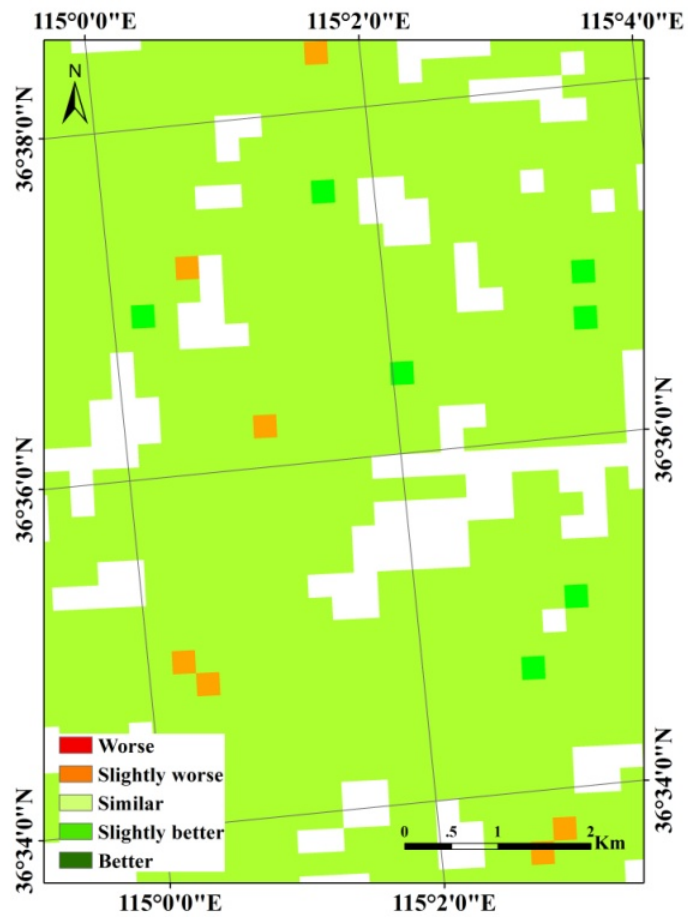

(c)

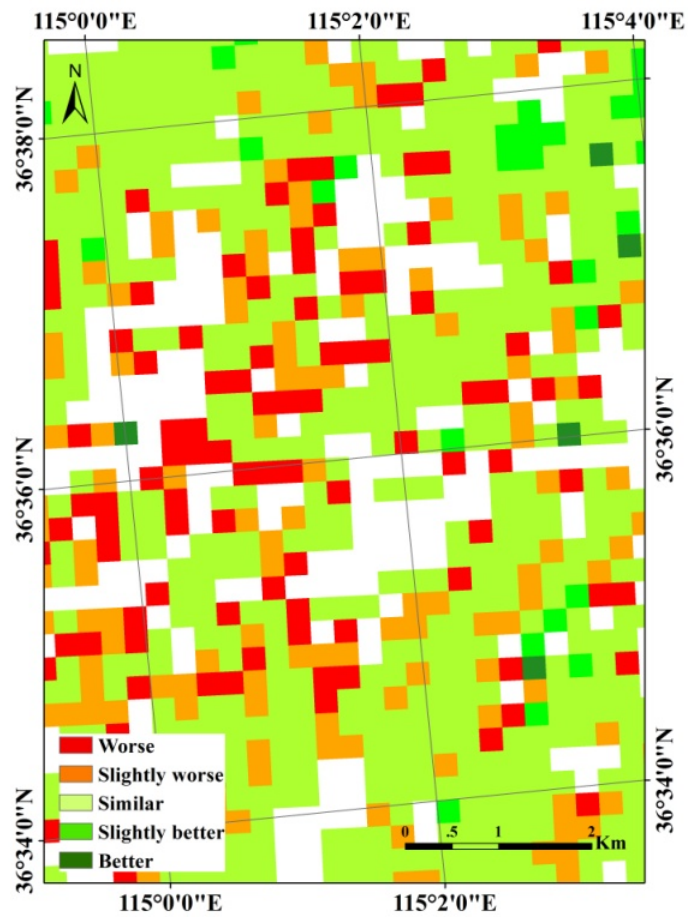

(d)

\subsection{Advantages and Shortcomings}

The most significant advantage of the proposed method is that it relies only on the identification of cropped and uncropped arable land. It is much easier to identify uncropped arable land than specific crops, especially when only incomplete growing season remote sensing data is available $[3,44]$. The accuracy for separating cropped and uncropped arable land was excellent (higher than 97\%) in our research, because the reflectance features and seasonal dynamic characteristics of cropped and uncropped arable land are distinctly different $[32,45]$. Previous research primarily explored different methods, both supervised and unsupervised, for crop classification. However, most of these methods were only feasible for identifying crops in small regions or areas with relatively low farmland fragmentation [46]. To achieve high accuracy for discriminating between different crops, high resolution images with a pixel size several times smaller than the land parcel size, as well as multi-temporal images are required [47]. These are unaffordable over large regions; consequently, it is impracticable to use crop type distribution maps to produce adjusted NDVI data for crop condition monitoring.

The second advantage of our approach is that it retrieved UALR-adjusted NDVI for pure cropped arable land by using a two-step approach. For the first step, MODIS pixels were considered as a mixture of only two endmembers - cropped and uncropped arable land. According to the linear mixing model (LMM), the band reflectance of a MODIS pixel is assumed to be a linear combination of uncropped and cropped arable land, weighted by the abundance of each endmember in the pixel. The reflectance of the cropped arable land endmember was retrieved by using a linear unmixing technique applied to the reflectance of the red and NIR bands. In the second step, NDVI values for the cropped arable land (UALR-adjusted NDVI) endmember were calculated using the endmember reflectance. In 
previous research, the NDVI value was simply assumed to be a linear combination of endmembers (cropped and uncropped arable land) NDVI [32], which introduces more uncertainty and larger errors than when an unmixing technique is applied to the band reflectance images.

The proposed method for crop condition assessment is transferable and directly applicable to other regions at different spatial scales as long as multi-temporal high resolution images and a timely updated land-cover map are available. Given these data, the method can be incorporated into crop monitoring systems. However, there are still some potential difficulties, which are not considered in this paper. It is a great challenge to obtain timely updated land-cover map at a high spatial resolution. If a timely and accurate updated land-cover map is not available, an out-of-date land-cover map, for instance a land-cover map produced five years ago, can also contribute to the crop assessment, but will introduce more error and uncertainty to the results, because of the land-cover change from year to year. Another concern is the impacts of weather condition on the quality of remote sensing images. This is the common disadvantage of optical remote sensing techniques [48]. Fortunately, there were only a few cloudlets in some of the HJ-1 CCD images we acquired in our research. In the regions with persistent cloud cover, cloud should be first identified and excluded in order to minimize the influence on crop assessment. Overall, the proposed method is simple, operational and can be incorporated into existing crop monitoring systems.

Further enhancements are certainly possible. This research assumes that the reflectance of the red and NIR bands for uncropped arable land is relatively constant throughout the study area and that the distribution of uncropped arable land does not change much during the winter crops growing season. In the future, the band reflectance of uncropped arable land will be given values based on different soil and climatic characteristics. A monthly or higher temporal frequency uncropped arable land map should be generated in order to capture the changes of uncropped arable land during the growing season. Furthermore, the crop condition assessment method is still based on a comparison of the snapshot and seasonal dynamics of NDVI images. The variation in crop phenophase from year to year is not considered. Further research will focus on incorporating the inter-annual variation of crop phenology into crop condition assessment. From an agronomy view, crop phenology is significantly related to accumulated temperature during the growing season. In the future, we will try to use accumulated temperature to normalize inter-annual comparisons of NDVI.

\section{Conclusions}

In this study, multi-temporal HJ-1 CCD images were used to generate an uncropped to total arable land ratio (UALR). This ratio was applied to time series MODIS reflectance imagery to retrieve an adjusted NDVI for a cropped arable land endmember. This UALR-adjusted NDVI and MODIS NDVI were then used for a crop condition assessment based on an inter-annual comparison of spatial variability and seasonal dynamics. Crop conditions derived from the two different NDVI datasets were compared, analyzed and evaluated for a study area in the North China Plain. The results indicate that the UALR-adjusted NDVI generates more accurate crop condition estimates, since it eliminates the influence of inter-annual variability in arable land utilization, adjusting for the differences in parts of a pixel that may not be cropped in one year, but may be cropped in another year. The proposed method yields more accurate monitoring results, simply by removing the variance in NDVI that is caused by 
the change in crop area, not the crop condition. Incorporating information on uncropped arable land can play a significant role in reducing the uncertainty from inter-annual variation in the cropping area for crop condition monitoring. Since it is even more important to capture accurate crop conditions in the early growing stage than acquiring the exact production after harvest, the suggested method could be an important addition to existing crop monitoring systems, following further evaluation in other major crop producing regions.

\section{Acknowledgments}

This paper was funded by National High Technology Research and Development Program of China (863 program) (Grant No. 2012AA12A307 and 2013AA12A302) and the Program of International Science and Technology Cooperation (Grant No. 2011DFG72280). The HJ-1 CCD data was provided by CRESDA. The authors would like to thank Meng Jihua for his support in the crop condition monitoring methodology and his contributions to the crop condition assessment. Thanks go to Anna van der Heijden and the anonymous reviewers for reviewing the manuscript and providing comments to improve the manuscript.

\section{Author Contributions}

Bingfang $\mathrm{Wu}$, the corresponding author, brings us the concept of the proposed method and mainly contributes to the discussion section. Miao Zhang writes up introduction, data, method and conclusion sections. Miao Zhang, together with Mingzhao Yu, Wentao Zou and Yang Zheng write up the method and results sections. Data processing and results analysis are done together by all the listed authors.

\section{Conflicts of Interest}

The authors declare no conflict of interest.

\section{References}

1. Meng, J.H.; Wu, B.F. Study on the crop condition monitoring methods with remote sensing. Remote Sens. Spat. Inf. Sci. 2008, 37, 945-950.

2. Jayne, T.S.; Rashid, S. The Value of Accurate Crop Production Forecasts. In Proceedings of Fourth African Agricultural Markets Program (AAMP) Policy Symposium, Lilongwe, Malawi, 6-10 September 2010.

3. Becker-Reshef, I.; Justice, C.; Sullivan, M.; Vermote, E.; Tucker, C.; Anyamba, A.; Small, J.; Pak, E.; Masuoka, E.; Schmaltz, J.; et al. Monitoring global croplands with coarse resolution earth observations: The Global Agriculture Monitoring (GLAM) Project. Remote Sens. 2010, 2, 1589-1609.

4. Wu, B.F.; Meng, J.H.; Li, Q.Z.; Yan, N.N.; Du, X.; Zhang, M. Remote sensing-based global crop monitoring: Experiences with China's cropwatch system. Int. J. Digit. Earth. 2014, 7, 113-137.

5. System Description of the WOFOST 6.0 Crop Growth Simulation Model Implemented in CGMS; Supit, I., Hooijer, A.A., van Diepen, C.A., Eds.; Joint Research Centre (JRC): Brussels, Belgium, 1994. 
6. Vossen, P.; Rijks, D. Early Crop Yield Assessment of the EU Countries: The System Implemented by the Joint Research Centre; Joint Research Centre (JRC): Brussels, Belgium, 1995.

7. Genovese, G. Introduction to the MARS Crop Yield Forecasting System, Document of the Working Party of the Statistics of Crop Products from the Agriculture Statistics Committee; Research Centre (JRC): Brussels, Belgium, 2001.

8. Genovese, G.P.; Fritz, S.; Bettio, M. A comparison and evaluation of performances among crop yield forecasting models based on remote sensing: Results from the geoland observatory of food monitoring. Int. Arch. Photogramm. Remote Sens. Spacial Inf. Sci. 2006, 36, 71-77.

9. Duveiller, G.; Lopez-Lozano, R.; Baruth, B. Enhanced processing of 1-km spatial resolution fAPAR time series for sugarcane yield forecasting and monitoring. Remote Sens. 2013, 5, 1091-1116.

10. FAO Global Information and Early Warning on Food and Agriculture (GIEWS). Available online: http://www.fao.org/giews/english/index.htm (accessed on 13 June 2014).

11. Famine Early Warning Systems Network. Available online: http://www.fews.net/about-us (accessed on 13 June 2014).

12. Space Applications Centre. Manual for Crop Production Forecasting Using Remotely Sensed Data; A Joint Project of Space and Ministry of Agriculture, Govt. of India, Technical Note, RSAF/SAC/CAPE-II/TN/46/95; Space Applications Centre: Ahmedabad, India, 1995.

13. Reichert, G.C.; Caissy, D. A Reliable Crop Condition Assessment Program (CCAP) Incorporating NOAA AVHRR Data, a Geographical Information System and the Internet, 2002. Available online: http://proceedings.esri.com/library/userconf/proc02/pap0111/po111.htm (accessed on 6 June 2014).

14. Fontana, D.C.; Melo, R.W.; Wagner, A.P.L.; Weber, E.; Gusso, A. Use of Remote Sensing for Crop Yield and Area Estimates in the Southern of Brazil. In Proceedings of ISPRS Archives XXXVI-8/W48 Workshop Remote Sensing Support to Crop Yield and Area Estimates; Stresa, Italy, 2006.

15. Satellite Data Availability, Methods and Challenges for the Assessment Of Climate Change and Variability Impacts on Agriculture; Toulios, L., Stancalie G., Eds.; European Science Foundation: Strasbourg, France, 2010.

16. Wu, B.F.; Meng, J.H.; Li, Q.Z. An integrated crop condition monitoring system with remote sensing. Trans. ASABE 2010, 53, 971-979.

17. Wu, B.F. Operational remote sensing methods for agricultural statistics. Acta Geogr. Sin. 2000, 55, 23-35.

18. Esquerdo, J.C.D.M.; Zullo, J.J.; Antunes, J.F.G. Use of NDVI/AVHRR time-series profiles for soybean crop monitoring in Brazil. Int. J. Remote Sens. 2011, 32, 3711-3727.

19. Justice, C.O. Monitoring the grasslands of semi-arid Africa using NOAA-AVHRR data. Adv. Space Res. 1986, 13, 219-222.

20. Huete, A.; Justice, C.; Liu, H. Development of vegetation and soil indices for MODIS-EOS. Remote Sens. Environ. 1994, 49, 224-234.

21. Moran, M.S.; Inoue, Y.; Barnes, E.M. Opportunities and limitations for image-based remote sensing in precision crop management. Remote Sens. Environ. 1997, 61, 319-346. 
22. Genovese, G.; Vignolles, C.; Nègre, T.; Passera, G. A methodology for a combined use of normalised difference vegetation index and CORINE land cover data for crop yield monitoring and forecasting. A case study on Spain. Agronomie 2001, 21, 91-111.

23. Papadavid, G.; Fasoula, D.; Hadjimitsis, M.; Perdikou, P.S.; Hadjimitsis, D.G. Image based remote sensing method for modeling black-eyed beans (Vigna unguiculata) Leaf Area Index (LAI) and Crop Height (CH) over Cyprus. Cent. Eur. J. Geosci. 2013, 5, 1-11.

24. Domrnikiotis, C.; Spiliotopoulos, M.; Tsiros, E.; Dalezios, N.R. Early cotton production assessment in Greece based on the combination of the drought vegetation condition index (VCI) and Bhalme and Mooley Drought Index (BMDI). Int. J. Remote Sens. 2004, 25, 5373-5388.

25. Meng, J.H. Research to Crop Growth Monitoring Indicators with Remote Sensing. Ph.D. Thesis, Chinese Academy of Sciences, Beijing, China, 2006.

26. Yang, Z.W.; Di, L.P.; Yu, G.P.; Chen, Z.Q. Vegetation Condition Indices for Crop Vegetation Condition Monitoring. In Proceedings of the 2001 IEEE International Geoscience and Remote Sensing Symposium (IGARSS), Vancouver, BC, Canada, 24-29 July 2011; pp. 3534-3537.

27. Wu, B.F.; Zhang, M.; Zeng, H.W.; Liu, G.S.; Chang, S.; Gommes, R. New Indicators for Global Crop Monitoring in CropWatch-Case Study in North China Plain. In Proceedings of the 35th International Symposium on Remote Sensing of Environment, Beijing, China, 22-26 April 2013.

28. Liu, S.; Mo, X.; Lin, Z.; Xu, Y.; Ji, J.; Wen, G.; Richey, J. Crop yield responses to climate change in the Huang-Huai-Hai Plain of China. Agric. Water Manag. 2010, 97, 1195-1209.

29. Shi, X.Z.; Yu, D.S.; Warner, E.D.; Sun, W.X.; Petersen, G.W.; Gong, Z.T.; Lin, H. Cross-reference system for translating between genetic soil classification of China and soil taxonomy. Soil Sci. Soc. Am. J. 2006, 70, 78-83.

30. Grieser, J.; Gommes, R.; Bernardi, M. New_locClim, the Local Climate Estimator of FAO. Geophysical Research Abstracts 2001: 08305. Available online: ftp://ext-ftp.fao.org/SD/ Reserved/Agromet/New_LocClim/ (accessed on 6 June 2014).

31. Zhang, M.W.; Zhou, Q.B.; Chen, Z.X.; Liu, J.; Zhou, Y.; Cai, C.F. Crop discrimination in Northern China with double cropping systems using Fourier analysis of time-series MODIS data. Int. J. Appl. Earth Obs. 2008, 10, 476-485.

32. Zhang, M.; Wu, B.F.; Meng, J.H.; Dong, T.F.; You, X.Z. Fallow Land Mapping for Better Crop Monitoring in Huang-Huai-Hai Plain Using HJ-1 CCD Data. In Proceedings of the 35th International Symposium on Remote Sensing of Environment, Beijing, China, 22-26 April 2013.

33. China Centre for Resource Satellite Data and Application, Technical Specification of Payloads of HJ-1A/1B/1C. Available online: http://www.cresda.com/n16/n92006/n92066/n98627/index.html (accessed on 13 June 2014).

34. Reverb ECHO, NASA's Earth Observation System Data and Information System (EOSDIS). Available online: http://reverb.echo.nasa.gov (accessed on 13 June 2014).

35. Wu, B.F.; Zhang, L.; Yan, C.Z.; Wang, Z.M. China Cover 2010: Methodology and Features. In Proceedings of 2010 GeoInformatics, Hong Kong, China, 15-17 June 2012.

36. Li, M.M.; Wu, B.F.; Yan, C.Z.; Zhou, W.F. Estimation of vegetation fraction in the upper basin of Miyun reservoir by remote sensing. Res. Sci. 2004, 26, 153-159. 
37. Jing, X.; Yao, W.Q.; Wang, J.H.; Song, X.Y. A study on the relationship between dynamic change of vegetation coverage and precipitation in Beijing's mountainous areas during the last 20 years. Math. Comput. Model. 2011, 54, 1079-1085.

38. Sellers, P.J.; Tucker, C.J.; Collatz, G.J.; Los, S.O.; Justice, C.O.; Dazlich, D.A.; Randall, D.A. A revised land surface parameterization (SiB2) for atmospheric GCMs. Part II: The generation of global fields of terrestrial biophysical parameters from satellite data. J. Clim. 1996, 9, 706-737.

39. Gutman, G.; Ignatov, A. The derivation of the green vegetation fraction from NOAA/AVHRR data for use in numerical weather prediction models. Int. J. Remote Sens. 1998, 19, 1533-1543.

40. Zeng, X.; Dickinson, R.E.; Walker, A.; Shaikh, M.; DeFries, R.S.; Qi, J. Derivation and evaluation of global 1-km fractional vegetation cover data for land modeling. J. Appl. Meteorol. 2000, 39, 826-839.

41. Congalton, R.G.; Green, K. Assessing the Accuracy of Remotely Sensed Data: Principles and Practices; Lewis Publishers: Boca Raton, FL, USA, 1999.

42. Meng, J.H.; Wu, B.F.; Li, Q.Z. A global crop growth monitoring system based on remote sensing. Int. Arch. Photogramm. Remote Sens. Spatial Inf. Sci. 2008, XXXVII, 1695-1698.

43. Guo, W.; Wang, R.; Zhou, S.; Zhang, S.; Zhang, Z. Genetic diversity and clonal structure of Phragmites australis in the Yellow River delta of China. Biochem. Syst. Ecol. 2003, 31, 1093-1109.

44. Kastens, J.H.; Kastens, T.L.; Kastens, D.L.; Price, K.P.; Martinko, E.A.; Lee, R.Y. Image masking for crop yield forecasting using AVHRR NDVI time series imagery. Remote Sens. Environ. 2005, 99, 341-356.

45. Cheng, W.F.; Zhou, Y.; Wang, S.X.; Han, Y.; Wang, F.T.; Pu, Q.Y. Study on the method of recognizing abandoned farmlands based on multispectral remote sensing. Spectrosc. Spect. Anal. 2011, 31, 1615-1620.

46. Zhang, M.; Li, Q.Z.; Wu, B.F. Investigating the Capability of Multitemporal Landsat Images for Crop Identification in High Farmland Fragmentation Regions. In Proceedings of the 2012 First International Conference on Agro-Geoinformatics (Agro-Geoinformatics), Shanghai, China, 2-4 August 2012.

47. Peña-Barragán, J.M.; Ngugi, M.K.; Plant, R.E.; Six, J. Object-based crop identification using multiple vegetation indices, textural features and crop phenology. Remote Sens. Environ. 2011, 115, 1301-1316.

48. Asner, G.P. Cloud cover in Landsat observations of the Brazilian Amazon. Int. J. Remote Sens. 2001, 22, 3855-3862.

(C) 2014 by the authors; licensee MDPI, Basel, Switzerland. This article is an open access article distributed under the terms and conditions of the Creative Commons Attribution license (http://creativecommons.org/licenses/by/3.0/). 